\title{
Ontogenesis of the socially extended mind
}

\author{
Action editors: Michele Merritt, Somogy Varga \\ Joel Krueger \\ Department of Philosophy, Durham University, 50 Old Elvet, Durham DH1 3HN, United Kingdom
}

Available online 14 March 2013

\begin{abstract}
I consider the developmental origins of the socially extended mind. First, I argue that, from birth, the physical interventions caregivers use to regulate infant attention and emotion (gestures, facial expressions, direction of gaze, body orientation, patterns of touch and vocalization, etc.) are part of the infant's socially extended mind; they are external mechanisms that enable the infant to do things she could not otherwise do, cognitively speaking. Second, I argue that these physical interventions encode the norms, values, and patterned practices distinctive of their specific sociocultural milieu. Accordingly, not only do they enhance and extend the infant's cognitive competence. They also entrain the infant to think and act in culturally appropriate ways. These physical interventions are thus arguably the earliest examples of social practices that scaffold the infant's cognitive development and shape the development of their cultural education.
\end{abstract}

(C) 2013 Elsevier B.V. All rights reserved.

Keywords: Extended cognition; Self-regulation; Attention; Emotion; Social cognition; Vygotsky

\section{Introduction}

The hypothesis of extended cognition (HEC) is the view that the physical basis of some cognitive processes may include not only brain processes but also structures and processes in the agent's environment. In "The Socially Extended Mind", Gallagher (2013) pursues a liberal interpretation of HEC. He defends the hypothesis of socially extended cognition (HSEC). According to HSEC, some cognitive processes occurring within sociocultural institutions (e.g., legal, educational, and religious systems) are supported by the procedures and social practices that comprise these institutions. These "mental institutions", as Gallagher refers to them, encode the collective wisdom of our cultural milieu and thus enable - and perhaps even constitute - some of the processes occurring within these institutions.

Gallagher notes that taking HSEC seriously opens up different research trajectories. One direction is to look at how HSEC relates to issues of development and social

E-mail address: joel.krueger@durham.ac.uk cognition. More specifically, Gallagher suggests that we might consider the family as ontogenetically the first institution. We can then look for the developmental roots of HSEC by asking "how basic embodied and situated processes of primary and secondary intersubjectivity pull the infant into cognitive habits that shape all further learning" (Gallagher, 2013, p. 7).

I here take up Gallagher's invitation to consider the family as a mental institution. Within this institution, I focus on some of the embodied practices that comprise early infant-caregiver interactions. Specifically, I focus on the repertoire of physical interventions (gestures, facial expressions, direction of gaze, body orientation, patterns of touch and vocalization, etc.) that caregivers use to regulate infant attention and emotion. First, I argue that, from birth, these interventions are part of the infant's socially extended mind; they are external mechanisms that enable the infant to do things she could not otherwise do, cognitively speaking. Second, I argue that like Gallagher's "mental institutions", these physical interventions encode the norms, values, and patterned practices distinctive of their specific sociocultural milieu. Accordingly, not only do these interventions enhance and extend the infant's 
cognitive competence. They also entrain the infant to think and act in culturally appropriate ways. These physical interventions are thus arguably the earliest examples of social practices that scaffold the infant's cognitive development and shape the development of their cultural education.

\section{Vygotsky and the social origins of cognition}

I begin by borrowing some concepts developed by Lev Vygotsky. These concepts, I suggest, help to illuminate Gallagher's claim that the family can be a kind of mental institution. They also help clarify how caregivers' physical interventions can become part of the infant's socially extended mind.

At the heart of Vygotsky's work is the distinction between "elementary" and "higher" mental processes (Vygotsky, 1978, p. 39). Vygotsky argues that cognitive processes like memory, attention, perception, and thought first emerge in biologically determined (i.e., elementary) form. We are born with certain cognitive capacities in light of our characteristic biological constitution. However, these elementary capacities rapidly undergo a qualitative transformation. In addition to a physical environment, we develop within a complex sociocultural milieu-structured and organized by various "extra-cortical connections" (Vygotsky, 1960) ${ }^{1}$-and the functioning of our elementary capacities quickly becomes more complex as we grow into this milieu and learn to think and act within it. Vygotsky (1978) writes:

Every function in the child's cultural development appears twice: first, on the social level, and later, on the individual level; first, between people (interpsychological), and then inside the child (intrapsychological). This applies equally to voluntary attention, to logical memory, and to the formation of concepts. All higher functions originate as actual relations between human individuals (p. 57).

For Vygotsky, this developmental trajectory means that higher mental processes (voluntary attention, memory, practical intelligence, conceptual thinking, etc.) have an external origin. They are mediated by features of the agent's sociocultural milieu, including its specific mental institutions, and thus owe their origin and characteristic manner of functioning to the cognitive resources housed within these institutions. ${ }^{2}$

\footnotetext{
${ }^{1}$ When he speaks of "extra-cortical connections" that facilitate cognitive functioning and development, Vygotsky seems to mean something very similar to Gallagher's "mental institutions".

${ }^{2}$ The precise relation between our biological and sociocultural development is complex - and one which Vygotsky failed to adequately resolve in his own work (Wertsch, 1985). Nevertheless, there are strands of empirical research that appear to support this idea (see, for example, Ansari, 2012; Hutchins, 2008).
}

We can get a firmer grip on this idea by considering Vygotsky's related notion of the "zone of proximal development" (ZPD). ZPD circumscribes the virtual space of a child's prospective mental development. It is within this space that the transition from interpsychological to intrapsychological functioning is made and higher mental functions emerge (Wertsch, 1985, p. 67). Vygotsky (1978) defines ZPD as

the distance between the actual developmental level as determined by independent problem solving and the level of potential development as determined through problem solving under adult guidance or in collaboration with more capable peers (p.86).

What is relevant for this discussion is the fact that the child's transition through various ZPDs is enabled by the social practices in which a particular ZPD is situated. In other words, ZPD maps onto Gallagher's analysis in that these practices help generate institution-specific cognitive events within the child - events that enhance the child's thinking and enable them to navigate a particular ZPD into higher levels of cognitive competence. We might therefore think of ZPD as the cognitive space where individual agents engage with the social practices distinctive of a particular mental institution. It is within this space that the socially extended mind emerges.

For example, consider how student cognition is shaped within the mental institution of the educational system. Particular teaching practices within this institution codify the cumulative wisdom of previous generations of teachers; they embody tried-and-true strategies for helping students learn and develop. Of course, the format of these strategies will likely vary according to the sociocultural context. But all teachers and mentors nurture student learning by providing various prompts, clues, leading questions, and individual and collaborative tasks designed to increase understanding. This is an essential part of the practice of teaching. And these strategies are pedagogical scaffolding that lift students out of their current level of understanding and enable them to move within a more advanced space of competence. Eventually, of course, the student moves permanently into this advanced space by acquiring the necessary expertise. But the process then begins anew; this is how learning occurs.

Skilled teachers thus use institutional practices - practices, one again, reflecting sociocultural particularities of time and place-to continually negotiate different ZPDs with their students. They tailor their instruction to meet the students' current level of competence while offering strategies and activities that gently nudge this competence into slightly more advanced levels (cf. Rogoff, 1990). In this way, then, does the mental institution of the educational system - including its constituent practices - extend the child's cognitive competence. Within this institution, 
the child can engage in cognitive activities they are incapable of doing outside of it (i.e., purely by appealing to their own internal resources).

To return to Gallagher's analysis, we can note that embodied practices are an important part of this mental institution and the process of negotiating different ZPDs. Consider, for example, the pedagogical function of gesture. Gestures play at least two critical roles in the learning process. First, gestures potentially signal to sensitive teachers what a student knows and does not know about a cognitive task. Hand gestures convey information not expressed in speech. ${ }^{3}$ A child's gesture, for example, can indicate an understanding of how to solve a mathematical equivalence task before the child can verbally articulate their strategy (Goldin-Meadow, 2003, p. 56). Sensitive teachers perceive this gesture-speech mismatch and tailor their instruction accordingly (Crowder, 1996; Crowder \& Newman, 1993).

Second - and more pertinent to our discussion-gestures assist the learning process by scaffolding student understanding into more advanced stages of cognitive competence. For example, students who mimic teachers' gestures learn more quickly than those who do not (Cook \& Goldin-Meadow, 2006; Goldin-Meadow \& Wagner, 2005). This is because gestures can be used to guide students' attention and represent actions and ideas; they afford a visuo-spatial format that encodes information in rich, stable, and highly-configurable ways - a public format shared with others (Becvar, Hollan, \& Hutchins, 2008). Moreover, the process of producing gestures appears to feed back onto the gesturer, altering and enhancing various aspects of their thinking-in-action (see Goldin-Meadow \& Beilock, 2010; see also Krueger, 2011b; Krueger, 2012). And apart from gesturing themselves, individuals profit even when they simply observe others gesturing. Grade school children learn and recall instruction more effectively when teachers produce both verbal and gestural formats than when teachers only provide instructions in speech (Goldin-Meadow \& Beilock, 2010). So, although the precise mechanism linking gesture and cognition remains elusive, it is nevertheless well-established that gestures (both produced and observed) positively inform the learning process. They organize students' attention and scaffold their transition through various ZPDs within the mental institution of the educational system.

Vygotsky's concept of ZPD can thus help begin to clarify the relation between mental institutions, the embodied practices that comprise them and the sorts of cognitive extension that emerge within their interaction. But this process is not something that begins only after the child enters school; nor is it confined to formal educational systems.

\footnotetext{
${ }^{3}$ Since gestures and speech have different representational formats, the information conveyed by each differs. Body language, facial expressions and the spontaneous gestures that accompany speech can even reflect thoughts, feelings, and intentions that the gesturer is not explicitly aware of possessing (see Beattie \& Shovelton, 1999; Broaders \& GoldinMeadow, 2010; Knapp, 1978).
}

Vygotsky, like Gallagher, insists that mental institutions are operative "from the very first day of a child's life" (quoted in Wertsch, 1985, p. 71). Following Vygotsky and Gallagher, I now consider the family as a cognitionenhancing mental institution. I look specifically at how physical interventions of caregivers function as embodied social practices that scaffold the infant's capacity for attention and emotion regulation. This scaffolding, I suggest, is an external mechanism for both cognitive enhancement as well as cultural entrainment.

\section{Attention and emotion regulation in early infancy}

A crucial part of cognitive development is attention management. Students must learn what to look for and what to ignore within a given task. This skill requires a more generalized level of attentional control. Here, environmental scaffolding plays a critical role. Classrooms and lecture halls place the instructor at the front of the room. The spatial configuration of the environment is organized to guide visual attention to the teacher, simplify perceptual choices, and heighten attentional focus (cf. Kirsh, 1995). This environmental arrangement also instantiates a sociocultural norm according to which those in teaching positions ought to be the center of attention and authority while speaking.

Gestures and other embodied practices likewise play a crucial role in this organizational process. This is especially true within the context of the family institution. For example, Zulu mothers, working in a culture where children in rural settings are expected to be less socially prominent than contemporary European or North American children, manage interpersonal space to sculpt infant attention. When dealing with fussy children, a mother will say "thula" (quiet) or "njega" (no) while leaning forward

so that her face and hands fill the infant's visual field. When this happens, new vocalizations and movements or reorientations of gaze by the infant are often "nipped in the bud" by dominating vocalizations [...] sometimes accompanied by increasingly emphatic hand-waving and even closer crowding of the infant's visual field (Spurrett \& Crowley, 2010, p. 306).

The mother in this way bodily manipulates the interpersonal space between herself and the infant; her gestures have cognitive significance in that they reduce competing distractions and regulate the child's attention and emotions. ${ }^{4}$ And they do so in a way that entrains the child to be sensitive to some of the sociocultural norms governing this context: namely, that she be quiet in the presence of adults. Repeated instances of this embodied practice thus shape the child's "cognitive habits" (Gallagher, 2013,

\footnotetext{
${ }^{4}$ See Krueger (2011b), for further discussion.
} 
p. 7) within this particular mental institution. The interaction is already a "culturally saturated" (Spurret \& Cowley, 2010 , p. 305) environment: the mother's gaze patterns, gestural configurations, response to infant distress, and prosodic properties of vocalizations all reflect the policies of this institution.

But this entrainment begins even earlier. The cognitive scaffolding provided by caregivers' embodied practices is especially crucial for the infant's psychosocial development during the first months when infants have little control over their attention or emotions. Newborns less than an hour old do have some attentional control. They can focus on the facial expressions of others and imitate these expressions (Meltzoff \& Moore, 1977; Meltzoff \& Moore, 1997); and they respond to expressions in ways suggesting basic recognition of their emotional significance (Kugiumutzakis, Kokkinaki, Makrodimitraki, \& Vitalaki, 2005). Newborns can also discriminate between self- versus externally-caused stimulation (touching their own cheek versus someone else doing it) (Rochat \& Hespos, 1997), and are capable of making olfactory discriminations between maternal amniotic fluid and the fluid of a stranger (Marlier, Schaal, \& Soussignan, 1998). Preterm infants orient toward pleasant sounding music as well as the sound of their mother's voice (Standley \& Madsen, 1990). Even very young babies thus exhibit a surprising degree of attentional and perceptual sophistication when it comes to attending to the faces, voices, smells, and touch of others. Intense periods of face-to-face interaction is the shared context in which these capacities are refined.

Nevertheless, there are developmental constraints on the character and degree of this attentional control. What is important for our purposes is that, unlike adult attention, early infant attention is primarily exogenous (bottom-up and involuntary) (Gopnik, 2009, pp. 106-123; Posner \& Rothbart, 1998). External objects and events catch infant attention and determine what they look at and how long they look at it. Adult perceivers, in contrast, exhibit endogenous (top-down, voluntary) control of attentional focus. While writing a paper, I may become momentarily distracted by a noisy conversation outside my office. But I can voluntarily shift my focus away from this distraction and resume my writing. This skill is not present in young infants. So, while the quality of their attention is rich, as the evidence surveyed earlier indicates, its inhibitory component is comparatively underdeveloped. ${ }^{5}$

\footnotetext{
${ }^{5}$ This developmental trajectory appears to be reflected at the neurochemical level. Cholinergic transmitters, which heighten attention, are abundant at birth; inhibitory transmitters, which suppress attention, develop later. Additionally, Luria's (1973) distinction between an early developing, largely involuntary biological attention system and a later developing, largely voluntary and socially-mediated attention system has been supported by more recent work (Posner \& Rothbart, 1998). Parietal and sensory systems involved in exogenous attention are thus online early, developmentally speaking, while top-down frontal regions controlling endogenous attention only mature later (Gopnik, 2008; Gopnik, 2009).
}

As we've already see with the example of Zulu mothers, the physical interventions of caregivers function as external mechanisms by which young infants inhibit and control their attention. But now consider breastfeeding, arguably the infant's earliest and most complex form of social interaction (Kaye, 1982). The rhythmic cycles and back-and-forth interplay of breastfeeding appears to play an important role in the infant's social cognitive development. Humans are the only mammalian infants who feed in short bursts. Even mothers who've never held a baby before will instinctively "jiggle" their infant as a prompt to resume feeding. This strategy works: infants are more likely to start feeding again after being jiggled than they are during the jiggling or if they'd not been jiggled at all (Kaye, 1982, p. 38). Within the dynamics of this exchange, mothers sculpt the infant's attention: their behavior is organized by the mother's touch and physical prompting. The infant is guided to notice salient environmental affordances by the jiggling (e.g., the nipple affording feeding) that, in light of her underdeveloped endogenous attention and lack of behavioral organization, she might not otherwise pick up on.

This exchange, I suggest, is an instance of the mother's embodied practices scaffolding the neonate through an early ZPD. The child is lifted into a sphere of cognitive (i.e., attentional) competence that she cannot inhabit without her mother's physical "instruction". Importantly, mothers adapt their "teaching" to the appropriate level: touch and gentle caresses are what the infant responds to at this stage of development. From the first feeding, mothers adapt to the bout-pause behavior of the infant's sucking (Alberts, Kalverboer, \& Hopkins, 1983). In response, the infant exhibits adaptive tactile behavior of her own: she is not merely a passive participant but reliably postpones her sucking until the mother ends her tactile behavior. This exchange - the general contours of which are predominantly shaped by the mother-is nevertheless a reciprocal, mutually-governed interaction, an early form of "participatory sense-making" (De Jaegher \& Di Paolo, 2007). Mother and infant form a coupled social system (Hopkins, 1983, p. 131). Within this dynamic a new cognitive process emerges that would not otherwise exist outside of this coupled system; the infant can temporarily realize a qualitatively new form of attentional focusing that exceeds the current phase of her cognitive development.

As the earlier Zulu mothers example showed, caregivers continue to scaffold the sociogenesis of infants' attentiondirecting processes beyond the first weeks and months of life. By the time they are 6 months old, more than half of infants will follow their mother's gaze; by one year, nearly all of them will do so (Corkum \& Moore, 1998; Scaife \& Bruner, 1975). Most infants point to objects by the time they are 9 months old (Murphy, 1978); at this stage parents increase their own use of pointing when interacting with infants (Bates, Camaioni, \& Volterra, 1975). And while infants initially respond to head movements in adults, by 18 months they track eye movements as well (Butterworth \& Jarrett, 1991). 
While there is surely a biological mechanism responsible for exogenous attention in infants, the repertoire of physical interventions caregivers use provide additional regulatory mechanisms that open up new channels of endogenous regulation. These external mechanisms allow the infant to exceed her current cognitive capacities: they "permit relatively rapid and selective direction of attention to objects at a distance as well as those close at hand, and allow parental influence over infant perceptual (and related cognitive) activity as well as motor activity" (Wexler, 2008, p. 102). Following Gallagher and Vygotsky, then, I suggest that this is an instance of an embodied practice, embedded within a mental institution (the family), that generates an extended cognitive process: "an external, socially organized attention [that] develops the child's voluntary attention" (Quoted in Luria, 1973, p. 262) and shapes both its characteristic manner of functioning as well as the self-regulatory mechanisms that direct attention in adult life. ${ }^{6}$

Regulating infant attention has consequences for their emotions. In virtue of their underdeveloped endogenous attention, within the first months of life young infants lack the ability to regulate their own emotions and generate positive affect (Rothbart, 1989). Again, they rely upon the mental institution of the family - and more specifically, the embodied practices of caregivers - to provide the external mechanisms that support this process.

Consider mutual affect regulation (Hobson, 2005; Tronick, 2005). This phenomenon refers to the way that infants and caregivers together establish a synchrony of feeling and expression. This sort of affective responsiveness to others is the bedrock of social engagement. However, it involves more than mere isomorphic matching of feeling. Rather, via the repertoire of physical interventions discussed previously, caregivers' actively modulate the attentional and affective character of these interactions in a way that is vital for the development of the infant's social sensitivity (Tronick, 2005).

From birth, infants are, as we've seen, socially sensitive: they respond differentially to the expressive "packages" of auditory-visual-tactile information that caregivers send their way (Beebe \& Gerstman, 1984). However, despite this innate or "primary" intersubjectivity (Trevarthen, 1979), it is caregivers who organize interpersonal contexts in specific ways, guiding their exogenous attention by scaffolding "infants within particular play frames characterized by exaggerated contours, marked changes of tempo, and systematic repetitions" (Rochat, Querido, \& Striano, 1999, p.951). Caregiver responses to infants call forth the next behavior within an interactive sequence (Hayes, 1984). The infant's emotional participation within these sequences is thus mediated by the physical interventions of the caregiver.

\footnotetext{
${ }^{6}$ Caregiver's physical interventions thus provide both synchronic scaffolding (i.e., within individual episodes) and diachronic scaffolding (i.e., supporting the long-term development of various embodied social skills).
}

This is especially clear when we consider the emergence of positive affect. For infants, this experience "require[s] the participation of an attuned adult who can both construct and coregulate the positive affect in a moment-by-moment process" (Feldman, 2007, p. 609). The crucial point is that the origin and regulation of these emotions is inherently dyadic. It is the caregiver who, via a repertoire of physical interventions, regulates the affective "vitality contours" (Stern, 1999) that give an interactive sequence its felt character. They do this by continually optimizing the stimulus value of their auditory-visual-tactile packages, crafted to keep the infant in an "optimal zone for play" between over-stimulation and under-arousal (Stern, 2010, p. 108).

For example, instead of matching the infant's expression of negative affect, the parent will initially express sympathetic emotions (e.g., uttering "Ooh, is someone unhappy?" in an exaggerated sing-song manner whilst frowning) but then elevate the shared affect by smiling broadly, leaning in, and adopting a jollier mode of expression (e.g., "C'mon, then! No need to be sad!" expressed with a rising inflection). The still face paradigm (Murray \& Trevarthen, 1985; Tronick, Als, \& Adamson, 1979) is a vivid example of the importance of caregiver scaffolding in constructing and co-regulating positive affect. Without the caregiver's positive facial expressions and emotional responsiveness, the infant immediately loses their self-regulatory capacities and the interaction disintegrates. Like breastfeeding, merely holding and gently rocking a distressed infant to help them achieve a quiet state is another instance of external affect regulation. These physical interventions are often accompanied by the singing of lullabies. Singing to infants solicits an embodied response: infants entrain their gestural, respiratory, and affective responses to the lullabies' rhythmic and melodic structure and, in so doing, are elevated into a phase of endogenous stability that exceeds their own self-regulatory capacities (Trehub \& Trainor, 1993; Trehub \& Trainor, 1998; see also Krueger 2011a).

Attentional control is thus closely tied to emotional selfregulation. Again, the salient point is that these regulatory processes are initially dependent on external mechanisms: the physical interventions of caregivers. Without this external scaffolding - embodied practices house within the mental institution of the family - the infant cannot achieve the same level of cognitive and behavioral competence. By highlighting caregivers' disproportionate influence on this process, we can thus motivate the claim that emotional and attentional ontogenesis is a socially extended process enabled by the institutional practices of the family (Greenwood, 2011).

Admittedly, it remains an open question just how early infants show signs of enculturation (cf. Spurret \& Cowley, 2010). But mental institutions are culturally saturated environments. And the embodied skills that comprise them encode the norms, values, and patterned practices distinctive of their sociocultural milieu. So will the way that these skills are deployed by family members in organizing and extending infant cognition and action. Infants' engagement 
with these practices thus marks the origins of their cultural education.

\section{Final thoughts}

A critic might suggest that the processes I've described (attentional control and emotion regulation) are not social-cognitive processes, properly speaking. ${ }^{7}$ The latter involve "mindreading" processes enabling us to predict and explain others' behavior, and to posit various propositional attitudes like beliefs, desires, intentions, etc., that animate this behavior. And there's no reason to think that these cognitive process depend upon mental institutions and thus have an extended structure. Rather, they rely upon various cognitive and/or neural mechanisms that reside inside individual heads: things like implicit inferences, simulation heuristics, Theory of Mind modules, or mirror neurons.

But this objection begs the question. For it is far from certain that social cognition depends upon, or can be reduced to, these kinds of intracranial mechanisms. Much recent work in philosophy of mind and developmental psychology challenges precisely this presupposition. ${ }^{8}$ The debate is too large to enter into here. The point is that one cannot simply assume this mentalistic, individualistic model of social cognition without further argument.

More substantively, we can note that these low-level perceptual and affective processes are crucial for building up interpersonal competence. They are the foundation of the various embodied skills that, even in adults, inform our ability to smoothly engage with and understand others. One cannot engage in high-level mindreading - for example, imaginatively projecting myself into another's "mental shoes", or reflecting on a range of possible motives or action explanations in order to understand their behavior-without summoning these bodily skills: attuning to the other person's facial expressions, gestures, gaze patterns, posture, emotions, and intentional actions, and sensing how these things relate to the surrounding context (i.e., the surrounding mental institution). As Gallagher puts it, these skills inform "cognitive habits" characteristic of mature social cognition. But at early stages of development-within the first weeks and months of life-these rudimentary skills are social-cognitive processes. They are processes that utilize available resources (i.e., embodied practices of family members) embedded within the mental institution of the family. Eventually, of course, these embodied skills are scaffolded into higher levels of develop-

\footnotetext{
${ }^{7}$ There is, apart from the objection briefly considered here, an additional objection that seems to be a permanent feature of extended mind discussions: the infamous coupling-constitution fallacy (Adams \& Aizawa, 2008). Space precludes a discussion of this issue. But see Krueger (2012).

${ }^{8}$ See, for example, (De Jaegher \& Di Paolo, 2007; Gallagher, 2008; Gallagher \& Zahavi, 2008; Leudar \& Costall, 2009; Reddy \& Morris, 2004).
}

ment and couple with other skills (reflective theorizing, imaginative simulating, etc.) to activate more cognitively sophisticated forms of social cognition.

Nevertheless, Gallagher and Vygotsky's point still stands. In order to understand the development of mature forms of cognition - including social cognition -we must trace their ontogenetic development as it unfolds interpsychologically, that is, within the dynamics of social interaction, support by embodied skills, and embedded in encompassing mental institutions. Building on Gallagher's analysis, this paper has considered the family as the earliest mental institution and, in so doing, briefly tried to shed light on the developmental origins of the socially extended mind.

\section{References}

Adams, F., \& Aizawa, K. (2008). The bounds of cognition. Oxford: Blackwell Publishing.

Alberts, E., Kalverboer, A. F., \& Hopkins, B. (1983). Mother-infant dialogue in the first days of life: An observational study during breastfeeding. Journal of Child Psychology and Psychiatry, and Allied Disciplines, 24(1), 145-161.

Ansari, D. (2012). Culture and education: New frontiers in brain plasticity. Trends in Cognitive Sciences, 16(2), 93-95. http:// dx.doi.org/10.1016/j.tics.2011.11.016.

Bates, E., Camaioni, L., \& Volterra, V. (1975). The acquisition of performatives prior to speech. Merrill-Palmer Quarterly, 21, 205-226.

Beattie, G., \& Shovelton, H. (1999). Mapping the range of information contained in the iconic hand gestures that accompany spontaneous speech. Journal of Language and Social Psychology, 18(4), 438-462. http://dx.doi.org/10.1177/0261927X99018004005.

Becvar, A., Hollan, J., \& Hutchins, E. (2008). Representational gestures as cognitive artifacts for developing theories in a scientific laboratory. Resources, Co-Evolution and Artifacts, 117-143.

Beebe, B., \& Gerstman, L. (1984). A method of defining "packages" of maternal stimulation and their functional significance for the infant with mother and stranger. International Journal of Behavioral Development, 7(4), 423-440. http://dx.doi.org/10.1177/ 016502548400700403.

Broaders, S. C., \& Goldin-Meadow, S. (2010). Truth is at hand: How gesture adds information during investigative interviews. Psychological Science, 21(5), 623-628. http://dx.doi.org/10.1177/0956797610366082.

Butterworth, G., \& Jarrett, N. (1991). What minds have in common is space: Spatial mechanisms serving joint visual attention in infancy. British Journal of Developmental Psychology, 9(1), 55-72. http:// dx.doi.org/10.1111/j.2044-835X.1991.tb00862.x.

Cook, S. W., \& Goldin-Meadow, S. (2006). The role of gesture in learning: Do children use their hands to change their minds? Journal of Cognition and Development, 7(2), 211. http://dx.doi.org/10.1207/ s15327647jcd0702_4.

Corkum, V., \& Moore, C. (1998). The origins of joint visual attention in infants. Developmental Psychology, 34(1), 28-38.

Crowder, Elaine. M. (1996). Gestures at work in sense-making science talk. The Journal of the Learning Sciences, 5(3), 173-208.

Crowder, E. M., \& Newman, D. (1993). Telling what they know: The role of gesture and language in children's science explanations. Pragmatics and Cognition, 1, 173-208.

De Jaegher, H., \& Di Paolo, E. (2007). Participatory sense-making. Phenomenology and the Cognitive Sciences, 6(4), 485-507. http:// dx.doi.org/10.1007/s11097-007-9076-9.

Feldman, R. (2007). On the origins of background emotions: From affect synchrony to symbolic expression. Emotion, 7(3), 601-611.

Gallagher, S. (2008). Direct perception in the intersubjective context. Consciousness and Cognition, 17(2), 535-543. http://dx.doi.org/ 10.1016/j.concog.2008.03.003. 
Gallagher, S. (2013). The socially extended mind. Cognitive Systems Research, 25-26, 4-12.

Gallagher, S., \& Zahavi, D. (2008). The phenomenological mind: An introduction to philosophy of mind and cognitive science. New York: Routledge.

Goldin-Meadow, Susan (2003). Hearing gesture: How our hands help us think. Cambridge: Belknapp Press.

Goldin-Meadow, S., \& Beilock, S. L. (2010). Action's influence on thought: The case of gesture. Perspectives on Psychological Science, 5(6), 664-674. http://dx.doi.org/10.1177/1745691610388764.

Goldin-Meadow, Susan., \& Wagner, S. M. (2005). How our hands help us learn. Trends in Cognitive Sciences, 9(5), 234-241. http://dx.doi.org/ 10.1016/j.tics.2005.03.006.

Gopnik, A. (2008). Why babies are more conscious than we are. Behavioral and Brain Sciences, 30(5-6), 503-504. http://dx.doi.org/ 10.1017/S0140525X0700283X.

Gopnik, A. (2009). The philosophical baby: What children's minds tell us about truth, love, and the meaning of life. New York: Farrar, Straus, and Giroux.

Greenwood, J. (2011). Contingent transcranialism and deep functional cognitive integration: The case of human emotional ontogenesis. Philosophical Psychology, 1-17. http://dx.doi.org/10.1080/ 09515089.2011.633752.

Hayes, A. (1984). Interaction, engagement and the origins of communication: Some constructive concerns. In L. Feagans, C. Garney, \& Golinkoff (Eds.), The origins and growth of communication (pp. 136-161). Norwood, NJ: Ablex.

Hobson, P. (2005). What puts jointness into joint attention? In N. Eilan, C. Hoerl, T. McCormack, \& J. Roessler (Eds.), Joint attention: communication and other minds (pp. 185-204). Oxford: Oxford University Press.

Hopkins, B. (1983). The development of early non-verbal communication: An evaluation of its meaning. Journal of Child Psychology and Psychiatry, and Allied Disciplines, 24(1), 131-144.

Hutchins, E. (2008). The role of cultural practices in the emergence of modern human intelligence. Philosophical Transactions of the Royal Society B: Biological Sciences, 363(1499), 2011-2019.

Kaye, K. (1982). The mental and social life of babies: How parents create persons. Chicago: Chicago University Press.

Kirsh, D. (1995). The intelligent use of space. Artificial Intelligence, 73(1-2), 31-68.

Knapp, M. L. (1978). Nonverbal communication in human interaction. New York: Holt, Rinehart, \& Winston.

Krueger, J. (2011a). Doing things with music. Phenomenology and the Cognitive Sciences, 10(1), 1-22. http://dx.doi.org/10.1007/s11097-0109152-4.

Krueger, J. (2011b). Extended cognition and the space of social interaction. Consciousness and Cognition, 20(3), 643-657.

Krueger, J. (2012). Seeing mind in action. Phenomenology and the Cognitive Sciences, 11(2), 149-173. http://dx.doi.org/10.1007/s11097011-9226-y.

Kugiumutzakis, G., Kokkinaki, T., Makrodimitraki, M., \& Vitalaki, E. (2005). Emotions in early mimesis. In J. Nadel \& D. Muir (Eds.), Emotional development: Recent research advances (pp. 161-182). Oxford: Oxford University Press.

Leudar, I., \& Costall, A. (Eds.). (2009). Against theory of mind. New York: Palgrave Macmillan.

Luria, A. R. (1973). The working brain. London: Penguin Books.

Marlier, L., Schaal, B., \& Soussignan, R. (1998). Neonatal responsiveness to the odor of amniotic and lacteal fluids: A test of perinatal chemosensory continuity. Child Development, 69(3), 611-623. http:// dx.doi.org/10.1111/j.1467-8624.1998.tb06232.x.

Meltzoff, A. N., \& Moore, M. K. (1977). Imitation of facial and manual gestures by human neonates. Science, 198, 75-78.

Meltzoff, A. N., \& Moore, M. K. (1997). Explaining facial imitation: A theoretical model. Early Development and Parenting, 6, 179-192.

Murphy, C. M. (1978). Pointing in the context of a shared activity. Child Development, 49(2), 371-380. http://dx.doi.org/10.2307/1128700.
Murray, L., \& Trevarthen, C. (1985). Emotional regulation of interactions between two month-olds and their mothers. In T. M. Field \& N. Fox (Eds.), Social perception in infants. Norwood, NJ: Ablex.

Posner, M., \& Rothbart, M. K. (1998). Attention, self-regulation, and consciousness. Philosophical Transactions of the Royal Society B: Biological Sciences, 353, 1915-1927.

Reddy, V., \& Morris, P. (2004). Participants don't need theories: Knowing minds in engagement. Theory \& Psychology, 14(5), 647-665. http:// dx.doi.org/10.1177/0959354304046177.

Rochat, P., \& Hespos, S. J. (1997). Differential rooting response by neonates: Evidence for an early sense of self. Early Development and Parenting, 6(34), 105-112.

Rochat, P., Querido, J. G., \& Striano, T. (1999). Emerging sensitivity to the timing and structure of protoconversation in early infancy. Developmental Psychology, 35(4), 950-957. http://dx.doi.org/10.1037/ 0012-1649.35.4.950.

Rogoff, B. (1990). Apprenticeship in thinking: Cognitive development in social context. Oxford: Oxford University Press.

Rothbart, M. K. (1989). Temperament and development. In G. A. Kohnstamm, J. E. Bates, \& M. K. Rothbart (Eds.), Temperament in childhood. New York: Wiley.

Scaife, M., \& Bruner, J. S. (1975). The capacity for joint visual attention in the infant. Nature, 253(5489), 265-266. http://dx.doi.org/10.1038/ $253265 \mathrm{a} 0$.

Spurret, D., \& Cowley, S. (2010). The extended infant: Utterance-activity and distributed cognition. In R. Menary (Ed.), The extended mind (pp. 295-323). Cambridge: MIT Press.

Standley, J. M., \& Madsen, C. K. (1990). Comparison of infant preferences and responses to auditory stimuli: Music, mother, and other female voice. Journal of Music Therapy, 27, 54-97.

Stern, D. (2010). Forms of vitality: Exploring dynamic experience in psychology, the arts, psychotherapy, and development. Oxford: Oxford University Press.

Stern, D. (1999). Vitality contours: The temporal contour of feelings as a basic unit for constructing the infant's social experience. In P. Rochat (Ed.), Early social cognition: Understanding others in the first months of life (pp. 67-80). Mahwah, NJ: Earlbaum.

Trehub, S. E., \& Trainor, L. J. (1998). Singing to infants: Lullabies and play songs. Advances in Infancy Research, 12, 43-77.

Trehub, S. E., \& Trainor, L. J. (1993). Listening strategies in infancy: The roots of music and language development. In S. McAdams \& E. Bigand (Eds.), Thinking in sound: The cognitive psychology of human audition. Oxford: Oxford University Press.

Trevarthen, C. (1979). Communication and cooperation in early infancy: A description of primary intersubjectivity. In M. Bullowa (Ed.), Before speech: The beginning of interpersonal communication (pp. 321-347). Cambridge: Cambridge University Press.

Tronick, E. Z., Als, H., \& Adamson, L. (1979). Structure of early faceto-face communicative interactions. In M. Bullowa (Ed.), Before speech: The beginning of interpersonal communication (pp. 349-370). Cambridge: Cambridge University Press.

Tronick, E. (2005). Why is connection with others so critical? The formation of dyadic states of consciousness and the expansion of individuals' states of consciousness: Coherence governed selection and the co-creation of meaning out of messy meaning making. In J. Nadel \& D. Muir (Eds.), Emotional development: Recent research advances (pp. 293-316). Oxford: Oxford University Press.

Vygotsky, L. (1960). Development of higher mental functions. Moscow: Publishing House of the Academy of Pedagogical Sciences.

Vygotsky, L. (1978). In M. Cole, V. John-Steiner, S. Scribner, \& E. Souberman (Eds.), Mind in society: The development of higher psychological processes. Cambridge: Harvard University Press.

Wertsch, J. V. (1985). Vygotsky and the social formation of mind. Cambridge, MA: Harvard University Press.

Wexler, B. (2008). Brain and culture: Neurobiology, ideology, and social change. Cambridge: MIT Press. 